\title{
Molecular Character, Phylogeny and Expression of Tomato LeNHX3 Gene Involved in Multiple Adverse Stress Responses
}

\author{
Jing Fan ${ }^{1, *}$, Jianping $\mathrm{Hu}^{2}$, Lanyang $\mathrm{Gao}^{3}$, Jinhua $\mathrm{Liao}^{1}$ and Mingyuan Huang ${ }^{1}$ \\ ${ }^{1}$ College of Life Science, Leshan Normal University, Leshan, 614004, P.R. China \\ ${ }^{2}$ College of Chemistry, Leshan Normal University, Leshan, 614004, P.R. China \\ ${ }^{3}$ Sichuan Academy of Botanical Engineering, Chengdu, 641200, P.R. China
}

\begin{abstract}
Crop production is severely affected by high salt stress. To obtain more salt-tolerant crops by genetic modification, it is crucial to explore some key genes associated with salt tolerance. LeNHX3 gene is considered one putative $\mathrm{Na}^{+} / \mathrm{H}^{+}$antiporter with the ability of improving plant salt tolerance by maintaining intracellular ionic balance in tomato, however, limited information about it has been reported. Here, we report the structure, phylogenetic evolution and expression of LeNHX3 gene from wild type tomato (Lycopersicon esculentum Mill cv. Ailsa Craig). Sequence analysis showed that LeNHX3 encodes a protein containing 10 transmembrane domains, with a typical conserved amiloride binding domain presented in the third transmembrane domain. An interesting discovery also showed that sequence of LeNHX3 was more conserved than its allele protein collected by GenBank (designated as LeNHX3-GB in this study) when compared with others $\mathrm{Na}^{+} / \mathrm{H}^{+}$antiporters. Homology modeling results showed that the structure of LeNHX3 protein consists mainly of $\alpha$-helix and random coil, it has similar tertiary structure to that of LeNHX3-GB, however, inter-residue interactions were found to be further strengthened in LeNHX3. Phylogenetic analysis showed LeNHX3 was clustered with vacuolar $\mathrm{Na}^{+} / \mathrm{H}^{+}$antiporters and has distant relationship to plasma membrane $\mathrm{Na}^{+} / \mathrm{H}^{+}$antiporters. Expression profiles analysis indicated LeNHX3 gene was constitutively expressed in roots, stems and leaves, its expression was also induced by salt, low temperature and abscisic acid. The results presented in this work provide new insights into LeNHX3 gene, it is particularly important that one new LeNHX3 allele from wild tomato was mined, which can serve as a candidate gene for improving plant stress tolerance by genetic engineering.
\end{abstract}

Keywords: Homology modeling, $\mathrm{LeNHX3}$ gene, $\mathrm{Na}^{+} / \mathrm{H}^{+}$antiporters, Phylogenetic evolution, Salt tolerance.

\section{INTRODUCTION}

Soil salinization has been one of the severest negative environmental constraints, nearly 7 percent of the total land, 20 percent of the cultivated area and 50 percent of the irrigated lands in the world are adversely affected by salinity stress [1-3], it disrupts the normal photosynthesis and carbohydrate metabolism of corps, with a consequence of plant growth retardation and yield reduction. Global agricultural sustainability is largely dependent on the improvement of crop salt tolerance [4]. Tomato is one of the most widely grown and consumed vegetables in the world [5], however, most of the cultivated tomatoes are highly or moderately sensitive to soil salinity, which results in substantially reducing the yields under salt stress $[6,7]$. Wild tomatoes are more salt-tolerant than cultivated tomatoes [8], they are suitable as the germplasms for mining genes for genetic improvement of salt tolerance in cultivated tomatoes.

In order to avoid occurrence of high salt toxicity in plants, $\mathrm{Na}^{+}$should be transported outside the cytosol or

*Address correspondence to this author at College of Life Science, Leshan Normal University, Leshan, Sichuan, 614004, P.R. China;

Tel: +86 18283336675; E-mail: fanjing972001@126.com inside the vacuoles, all the processes can be mediated by $\mathrm{Na}^{+} / \mathrm{H}^{+}$antiporter, a protein conferring salt tolerance for plant by maintaining ion homeostasis in cells [9]. To date, many $\mathrm{Na}^{+} / \mathrm{H}^{+}$antiporters have been cloned and characterized. AtNHX1 was the first vacuolar $\mathrm{Na}^{+} / \mathrm{H}^{+}$ antiporter isolated from Arabidopsis thaliana, its overexpression led to increased salt tolerance of Arabidopsis thaliana, peanut and maize $[10,11] . \mathrm{Na}^{+} / \mathrm{H}^{+}$antiporters from other species also confer salt tolerance in plants, for example, the vacuolar $\mathrm{Na}^{+} / \mathrm{H}^{+}$antiporter $S b N H X I$ gene from extreme halophyte Salicornia brachiata conferred salt tolerance for Jatropha curcas [12]. In tomato, several $\mathrm{Na}^{+} / \mathrm{H}^{+}$ antiporters have also been reported. LeNHX2, one $\mathrm{Na}^{+} / \mathrm{H}^{+}$ antiporter located in vacuole, is an important determinants for salt tolerance of tomato $[13,14]$. LeNHX3 is another $\mathrm{Na}^{+} / \mathrm{H}^{+}$antiporter in tomato, a positive correlation was found between its expression level and salt tolerance in tomato [15], however, more molecular information about it is still lacking. In this study, structure, phylogeny and expression profiling of LeNHX3 from wild type tomato (Lycopersicon esculentum Mill cv. Ailsa Craig) were analyzed. This work is helpful for us to explore more information of LeNHX3 and improve plant abiotic stress tolerance by genetic engineering in the future. 
Table 1. Comparison of $\mathrm{Na}^{+} / \mathrm{H}^{+}$antiporters from different species.

\begin{tabular}{|c|c|c|c|c|c|}
\hline Protein Name & Species & $\begin{array}{c}\text { GenBank Accession } \\
\text { Number }\end{array}$ & $\begin{array}{l}\text { Numbers of } \\
\text { Amino Acid }\end{array}$ & $\begin{array}{c}\text { Molecular Weight } \\
\text { (Da) }\end{array}$ & $\begin{array}{c}\text { Theoretical } \\
\text { Isoelectric Point }\end{array}$ \\
\hline LeNHX3 & $\begin{array}{c}\text { Solanum lycopersicum (wild type, } \\
\text { Ailsa Craig) }\end{array}$ & - & 537 & 59421.5 & 8.55 \\
\hline LeNHX3-GB & Solanum lycopersicum & CAK12754.1 & 537 & 59443.5 & 8.54 \\
\hline InNHX2 & Ipomoea nil & BAD91200 & 536 & 59317.6 & 7.17 \\
\hline CmNHX1 & Chrysanthemum $x$ morifolium & ABN71591 & 550 & 61085.3 & 6.46 \\
\hline AgNHX1 & Atriplex gmelini & BAB11940 & 555 & 61504.8 & 6.70 \\
\hline BnNHX2 & Brassica napus & ACZ92142 & 542 & 59931.1 & 7.67 \\
\hline ZmNHX2 & Zea mays & NP001105531 & 540 & 59808.2 & 8.25 \\
\hline MzNHX1 & Malus zumi & ADB80440 & 544 & 60474.0 & 8.85 \\
\hline VvNHX1 & Vitis vinifera & AAV36562 & 541 & 60137.2 & 7.24 \\
\hline SbNHX1 & Salicornia brachiata & ACA33931 & 560 & 62322.7 & 6.43 \\
\hline PeNHX3 & Populus euphratica & ACU01854 & 545 & 60293.7 & 8.13 \\
\hline TaNHX2 & Triticum aestivum & AAK76738 & 538 & 59082.4 & 8.41 \\
\hline GhNHX1 & Gossypium hirsutum & AAM54141 & 543 & 60089.5 & 7.20 \\
\hline KcNHX2 & Karelinia caspia & ABC18331.1 & 550 & 61079.5 & 6.36 \\
\hline HtNHX1 & Helianthus tuberosus & ABM17091.1 & 549 & 60744.2 & 6.90 \\
\hline PtNHA1 & Puccinellia tenuiflora & EF440291 & 1137 & 125500.2 & 6.48 \\
\hline CsSOS1 & Cucumber & AFD64618.1 & 1144 & 127272.0 & 6.30 \\
\hline OsSOS1 & Oryza sativa & AAW33875.1 & 1148 & 127917.8 & 6.77 \\
\hline
\end{tabular}

Note: LeNHX3-GB indicates the LeNHX3 protein collected in Genbank.

\section{MATERIALS AND METHODS}

\subsection{Plant Materials}

Mature seeds of Lycopersicon esculentum Mill. cv. Ailsa Craig were sanitized with 5\% sodium hypochlorite and then germinated on 1/2 Murashige and Skoog (MS) medium, after grown at $25^{\circ} \mathrm{C}$ in complete darkness for one week, seeds were incubated under $16 \mathrm{~h}$ light and $8 \mathrm{~h}$ dark photoperiod cycles until seedlings reached the height of about 8 centimeters, after treated with $200 \mathrm{mM} \mathrm{NaCl}, 150 \mathrm{mM}$ mannitol, low temperature $\left(4^{\circ} \mathrm{C}\right)$ and $10 \mu \mathrm{M}$ Abscisic acid for $6 \mathrm{~h}$, all samples were then collected and frozen immediately in liquid nitrogen and stored at $-80^{\circ} \mathrm{C}$ refrigerator for RNA extraction.

\subsection{Protein Sequences}

The LeNHX3 gene has been cloned from wild type tomato (Lycopersicon esculentum Mill. cv. Ailsa Craig) and sequenced in our previous study [16]. In this study, amino acid sequence of LeNHX3 was deduced from its cDNA sequence, sequences of other $\mathrm{Na}^{+} / \mathrm{H}^{+}$antiporters were got from the protein database maintained by NCBI (http://www.ncbi.nlm. nih.gov/protein), for more details see Table 1.
2.3. Molecular Characteristics, Structure and Phylogenetic Relationship Analysis

Physical characteristics of LeNHX3 protein were deduced by protparam program at the ExPASy server (http://au.expasy.org/tools/protparam.html) with default parameters. Transmembrane analysis was performed by TMHMM server (http://www.cbs.dtu.dk/services/ TMHMM $-2.0 /$ ) with default parameters. Multiple sequence alignments and amino acid sequence homology analysis between LeNHX3 and other $\mathrm{Na}^{+} / \mathrm{H}^{+}$antiporters were performed by DNAMAN software (Lynnon corporation, Quebec, Canada) using the full alignment method. To construct threedimensional structure of LeNHX3, fasta format sequence of which was submitted to the Swiss-model workspace (http://swissmodel.expasy.org/workspace/index. php), the template hits for LeNHX3 protein was then searched using template identification tool [17], the resulting structure with the largest sequence homology to LeNHX3 was used as template, homology modeling of LeNHX3 was then performed using alignment mode in Swiss-Model, the resulting structure was viewed using pymol software (version 0.99, DeLano Scientific LLC, South San Francisco, California, USA). On the basis of amino acid sequence alignments by Clustalx1.83 (EMBL-EBI, Cambridge, UK) using multiple alignment mode, phylogenetic evolutionary 
analysis was completed using MEGA software version 5.0 (www.megasoftware.net), the neighbor-joining (NJ) tree was generated using the p-distance method with complete deletion option and 1000 bootstrap replicates.

\subsection{Tissue Specific and Stress Induced Expression of LeNHX3 Gene}

Total RNA for tissue specific expression was extracted from the mashed roots, stems and leaves. Total RNA for stress induced expression was extracted from the plantlets induced by salt, mannitol, low temperature and ABA using RNAprep Kit (Tiangen, Beijing, China), their cDNA were synthesised using cDNA synthesis kit (TaKaRa, Dalian, China). RT-PCR primers were designed with Primer 5.0 software, the primer sequences for LeNHX3 gene amplification were as follows: 5'-GACTTATGCGAGG TGCTGTT-3' (forward primer) and 5'-CACTTGGTTCCG TTGGTGAT-3' (reverse primer). The housekeeping gene ubiquitin III (Ubi3) was assayed as an internal control (GenBank accession no. X58253.1), the primer sequences were 5'-AGAAGAAGACCTACACCAAGCC-3' (forward primer) and 5'-TCCCAAGGGTTGTCACATACATC-3' (reverse primer). The PCR amplification program was as follows: $94^{\circ} \mathrm{C}$ for $5 \mathrm{~min}$ (initial denaturing), followed by 30 cycles of $94^{\circ} \mathrm{C}$ for $30 \mathrm{~s}$ (denaturation), $55^{\circ} \mathrm{C}$ for $30 \mathrm{~s}$ (annealing) and $72^{\circ} \mathrm{C}$ for $30 \mathrm{~s}$ (extension), with a final extension at $72^{\circ} \mathrm{C}$ for $10 \mathrm{~min}$, PCR products were then analyzed on $1.0 \%$ ethidium bromide-stained agarose gel.

\section{RESULTS}

\subsection{Physiochemical Properties}

To analyze the physicochemical parameters of different $\mathrm{Na}^{+} / \mathrm{H}^{+}$antiporters, the protein sequences of 3 plasma membrane (PtNHA1, CsSOS1, OsSOS1) and 15 vacuolar type $\mathrm{Na}^{+} / \mathrm{H}^{+}$antiporters were analyzed using ProtParam tool. The results showed that LeNHX3 protein encoding a polypeptide containing 537 amino acid residues with a predicted molecular weight of $59421.5 \mathrm{Da}$ and theoretical isoelectric point of 8.55 , it was smaller in molecular weight, but with larger theoretical isoelectric point than other $\mathrm{Na}^{+} / \mathrm{H}^{+}$ antiporters (Table 1). To analyze the distribution of transmembrane domain, amino acid sequence of LeNHX3 was analyzed using TMHMM 2.0, the result indicated that LeNHX3 was consisted of ten transmembrane domains between the residues 21 to 43,53 to 72,77 to 99,114 to 136 , 218 to 240,270 to 292,304 to 326,341 to 363,384 to 402 , 417 to 436 , respectively (Fig. 1).

\subsection{Sequence Alignments and Homology Analysis}

To identify the conserved domain presented in LeNHX3 protein and compare the sequence differences between LeNHX3 and other $\mathrm{Na}^{+} / \mathrm{H}^{+}$antiporters, multiple sequence alignments of LeNHX3 against other 14 known vacuolar type $\mathrm{Na}^{+} / \mathrm{H}^{+}$antiporters were performed using full alignment method of DNAMAN software. The result revealed that the conserved amiloride-binding domain LFFIYLLPPI was present in the third transmembrane domain at the $\mathrm{N}$ terminal of LeNHX3. Interesting, by comparing the amino acid sequence of LeNHX3 with its allele-associated protein LeNHX3-GB, three amino acid substitutions between them were found, it was a Tyrosine to Histidine substitution at position $143(\mathrm{Y} 143 \mathrm{H})$, a Proline to Serine substitution at position $346(\mathrm{P} 346 \mathrm{~S})$ and a Glycine to Alanine substitution at position 399 (G399A) in LeNHX3 protein, respectively. The Serine at position 346 and Alanine at position 399 were located in the eighth and ninth transmembrane domain of LeNHX3, both of them were more conserved than that of LeNHX3-GB (Fig. 1), this indicated that the Serine-346 and Alanine-399 are important for transport function of LeNHX3.

\subsection{Modeling the Three-Dimensional Structure of LeNHX3}

To establish the tertiary structure of LeNHX3 and compare the structure differences between LeNHX3 and its allele associated protein LeNHX3-GB, their protein sequences were homology-modeled using the SWISSMODEL server in alignment model, structures were constructed based on the sequence ranging from Phenylalanine at position 3 (Phe 3) to Isoleucine at position 386 (Ile 386) of LeNHX3 and LeNHX3-GB proteins, structure of NapA (PDB code, 4bwzA) was chosen as the template for modeling. The results showed that LeNHX3 and LeNHX3-GB proteins were primarily composed of $\alpha$-helix and random coil (Fig. 2A, B), the conserved amiloridebinding domain LFFIYLLPPI and the different residues at position 143 and 346 were located at the protein surface (Fig. 2C, D). Although LeNHX3 showed high similarity with the structure of LeNHX3-GB, changes of inter-residue interactions were still found. In LeNHX3, one oxygen of Histidine residue at position 143 (H143) was found to interact with the nitrogen of Glycine residue at position 147 (G147), with a distance of $3.36 \AA$, two nitrogen atoms of H143 were involved in the interface with the oxygen and nitrogen of Asparagine residue at position 140 (N140), including formation of two sets of hydrogen bonds with separation of 2.86 and $3.10 \AA$ (Fig. 2E). We also found the Serine residue at position 346 (S346) interacted with the Glutamine residue at position 343 (Q343) in LeNHX3, with a single polar contact of $3.36 \AA$ (Fig. 2F). However, only the residue Tyrosine at position 143 (Y143) formed two polar contacts with the Glycine at position 147 (G147) and the Asparagine at position 140 (N140) in LeNHX3-GB, resulting in two hydrogen bonds with distance of 3.34 and $2.86 \AA$, respectively (Fig. 2G).

\subsection{Phylogenetic Analysis of LeNHX3 and other $\mathrm{Na}^{+} / \mathrm{H}^{+}$ Antiporters}

In order to ascertain the evolutionary relationships between the LeNHX3 and $\mathrm{Na}^{+} / \mathrm{H}^{+}$antiporters from other plant species, a phylogenetic tree was constructed. The result showed that LeNHX3 has close phylogenetic relationship to the vacuolar type antiporters, it falls into the same clade with tomato LeNHX3-GB and InNHX2 from Ipomoea nil. However, LeNHX3 showed distant genetic relationship to plasma-membrane type $\mathrm{Na}^{+} / \mathrm{H}^{+}$antiporters (Fig. 3), this allows us to confirm that LeNHX3 is a typical vacuolar $\mathrm{Na}^{+} / \mathrm{H}^{+}$antiporter. 


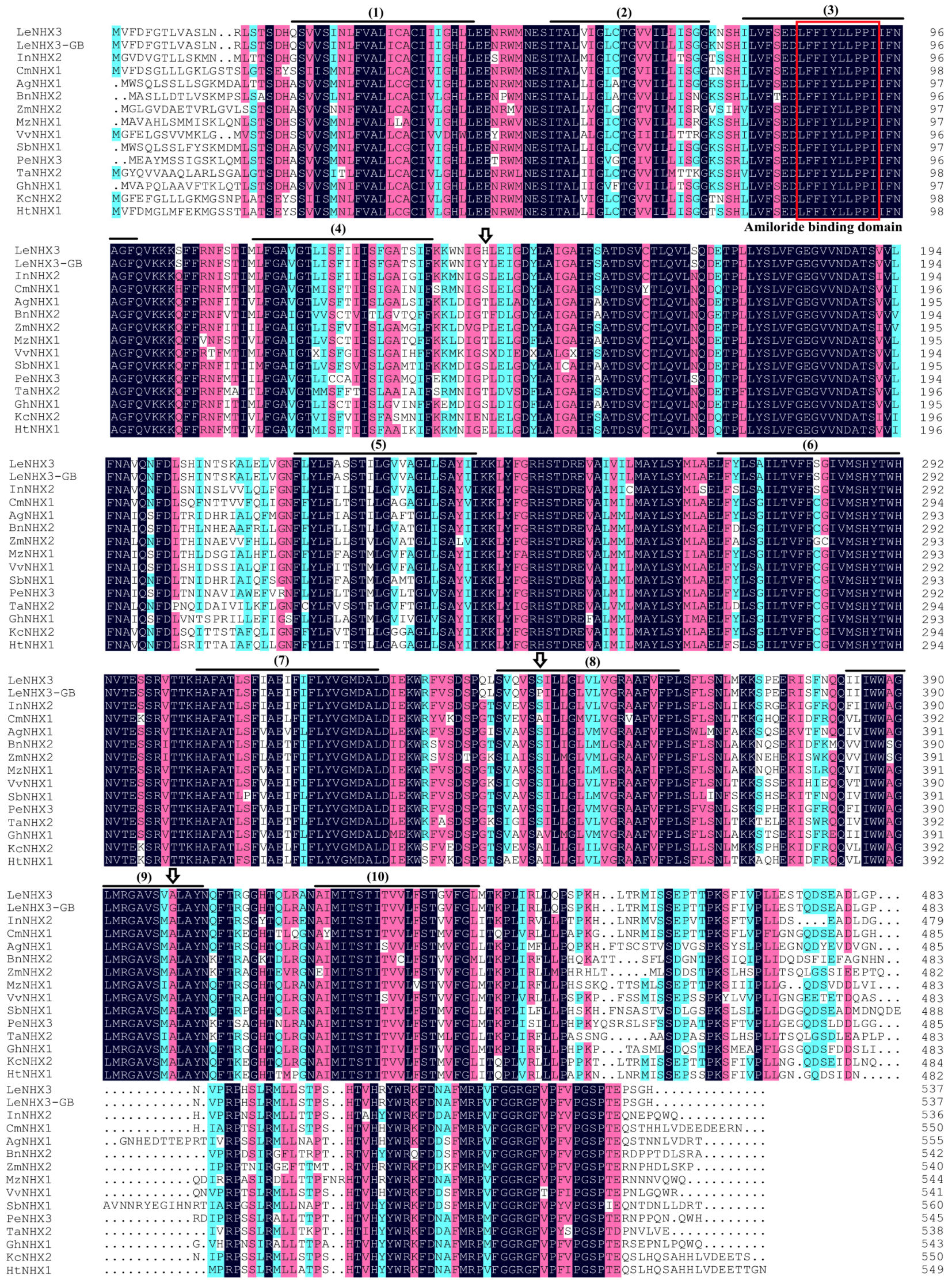

Fig. (1). Multiple sequence alignments of LeNHX3 with $\mathrm{Na}^{+} / \mathrm{H}^{+}$antiporters from other species. The box indicates the conserved amiloridebinding site, the different amino acids in LeNHX3 and LeNHX3-GB are indicated by arrows, the 10 transmembrane domains are indicated by an overline respectively. 


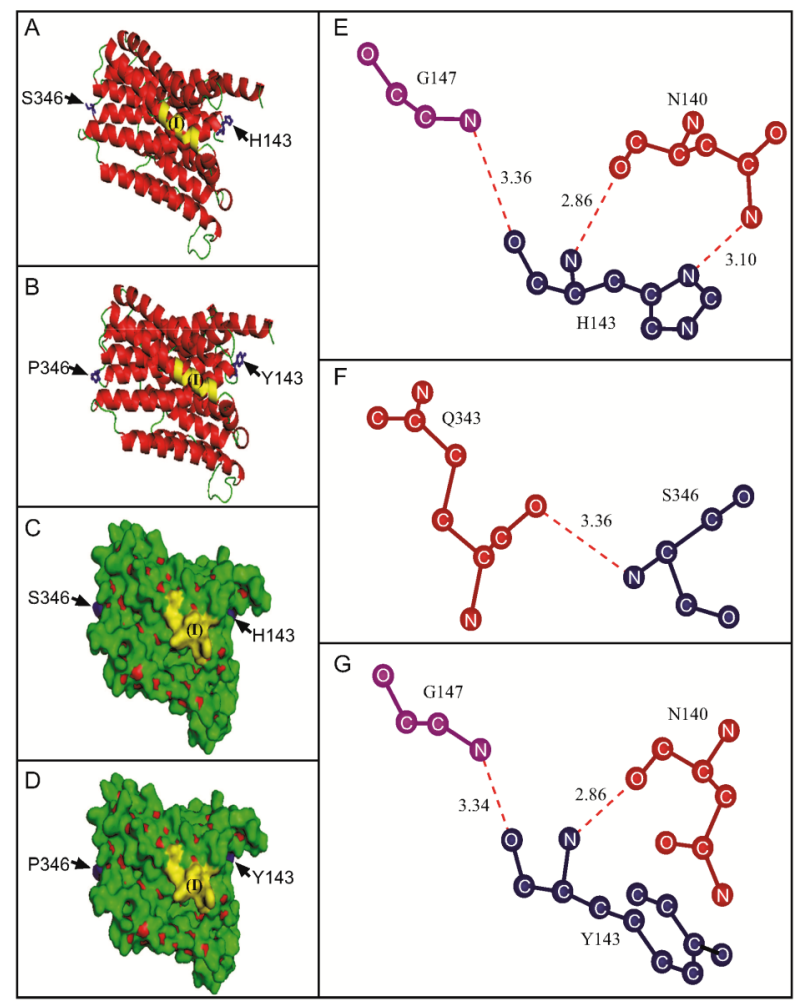

Fig. (2). Homology modeling and comparison of the interactions for different residues in LeNHX3 and LeNHX3-GB. Three-dimensional structures of LeNHX3 and LeNHX3-GB are shown in cartoon and surface representations, with $\alpha$-helices colored red, coiled regions colored green, the conserved amiloride-binding domain colored in yellow and labeled as (I). Different residues at position of 143 and 346 of LeNHX3 and LeNHX3-GB were colored blue and indicated by arrows. (A) Cartoon representation of LeNHX3. (B) Cartoon representation of LeNHX3-GB. (C) Surface representation of LeNHX3. (D) Surface representation of LeNHX3-GB. The different residue interactions in LeNHX3 and LeNHX3-GB were shown in stick-sphere representations, hydrogen bonds were shown as dashed red lines. (E) Interaction of the Histidine residue at position 143 (H143) with the Glycine residue at position 147 (G147) and the Asparagine residue at position 140 (N140) in LeNHX3. (F) Interaction of the Serine residue at position 346 (S346) with the Glutamine residue at position 343 (Q343) in LeNHX3. (G) Interaction of the Tyrosine residue at position 143 (Y143) with the residue Glycine at position 147 (G147) and the residue Asparagine at position 140 (N140) in LeNHX3-GB.

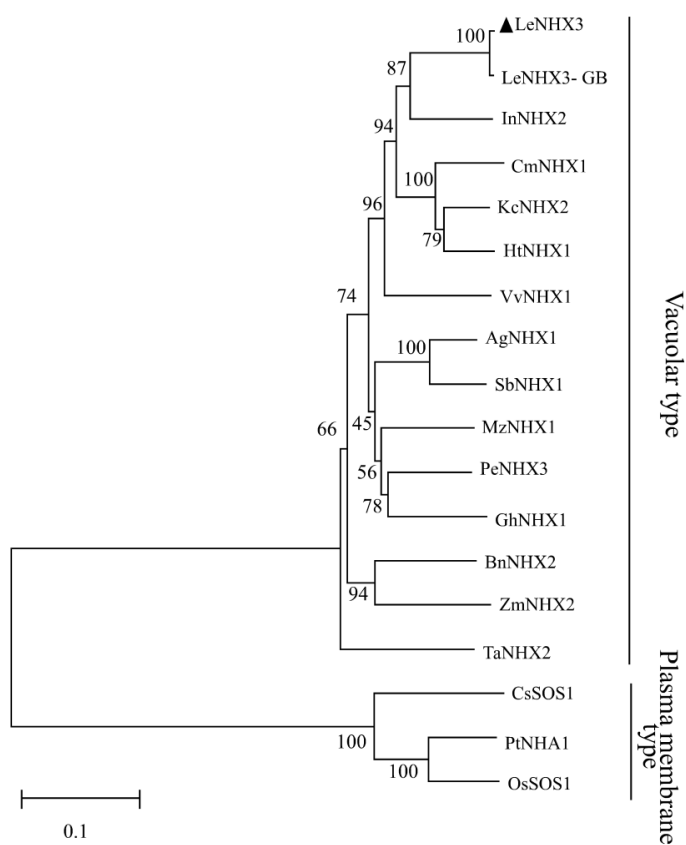

Fig. (3). Phylogenetic analysis of LeNHX3 and other $\mathrm{Na}^{+} / \mathrm{H}^{+}$ antiporters. Numbers near the nodes represent the percentage of 1000 bootstrap replicates that support each node, the scale bar corresponds to 0.1 amino acid substitutions per site.

\subsection{Expression Patterns of $\mathrm{LeNHX} 3$ Gene}

To investigate the expression patterns of LeNHX3 gene, specific tissue expressions of $L e N H X 3$ in various tissues were examined by RT-PCR. The results showed that LeNHX3 was constitutively expressed in the leaves, stems and roots (Fig. 4A), this suggested that LeNHX3 is essential for the normal function of wild type tomato. Abiotic stress induced expression showed that LeNHX3 was induced by salt, which demonstrated the potent role of LeNHX3 in salt tolerance in wild type tomato. Interesting, the transcript levels of $L e N H X 3$ were also up-regulated by low temperature and ABA, and the highest expression occurs at low temperature treatment, however, the transcript was not obviously induced by mannitol, this indicated that LeNHX3 is involved in cross talk between salt, low temperature and ABA in tomato (Fig. 4B).

\section{DISCUSSION}

$\mathrm{Na}^{+} / \mathrm{H}^{+}$antiporter maintains a steady salt homeostasis by transporting $\mathrm{Na}^{+}$and $\mathrm{H}^{+}$ions across the cell membrane [18]. Due to wild genotype tomatoes are usually more salt tolerant than the cultivar, they are regarded as ideal gene donor for improving salt tolerance capacity of cultivated tomatoes [19]. The putative $\mathrm{Na}^{+} / \mathrm{H}^{+}$antiporter LeNHX3 gene has been 


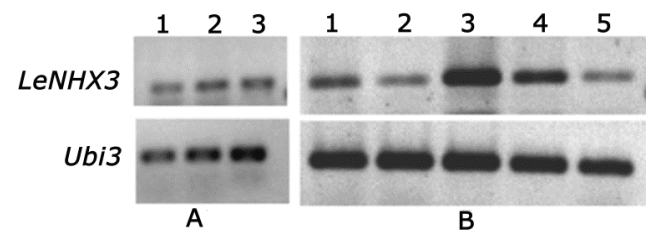

Fig. (4). Expression of $L e N H X 3$ gene. (A) RT-PCR analysis of LeNHX3 gene (upper) and the internal control Ubi3 gene (lower) in different tissues. Lane 1, roots; lane 2, stems; lane 3, leaves. (B) Abiotic stress induced expression of LeNHX3 gene (upper) and the internal control Ubi3 gene (lower). Lane 1, salt; lane 2, mannitol; lane 3, low temperature; lane 4, ABA; lane 5, untreated.

previously cloned by us from wild type tomato [16], three amino acids were found different in comparison with its homologous LeNHX3-GB, and two of they were more likely to appear in most of the $\mathrm{Na}^{+} / \mathrm{H}^{+}$antiporters (Fig. 1). It has been previously reported that base substitutions can significantly alter gene function, for example, the $\mathrm{Na}^{+} / \mathrm{H}^{+}$ antiporter SOS1 gene in Arabidopsis thaliana is essential for plant salt tolerance, however, a single base substitution in SOS1 made plants show salt-hypersensitive and low $\mathrm{K}^{+}$ affinità $[20,21]$, thus we speculate that the substituted amino acids in LeNHX3 may confer plants more pronounced salt tolerance. It has been demonstrated that homology model is accurate enough to predict protein structures in wide ranging applications [22, 23], their folds are stabilized by inner residues contacts [24, 25]. Kozachkov and Padan have reported that two residues at position 136 and 399 of $\mathrm{Na}^{+} / \mathrm{H}^{+}$ antiporter NhaA in Escherichia coli were closely related to the conformational changes of protein [26]. In this study, no obvious conformational changes were observed between LeNHX3 and its homologues LeNHX3-GB, however, the substituted residues 143 (H143) and 346 (S346) in LeNHX3 strengthened inter-residue interactions in comparison with LeNHX3-GB, those make LeNHX3 conformation more stable than LeNHX3-GB (Fig. 2E-G). Evolutionary tree is commonly used to infer phylogenetic relationships between species [27], our results showed LeNHX3 and LeNHX3-GB formed the same clade with vacuolar $\mathrm{Na}^{+} / \mathrm{H}^{+}$antiporter InNHX2 [28], but with more distantly related to the plasma membrane $\mathrm{Na}^{+} / \mathrm{H}^{+}$antiporters CsSOS1, PtNHA1 and OsSOS1 [29-31] (Fig. 3), so we conclude that LeNHX3 and LeNHX3-GB play important roles in transporting excess cytoplasmic $\mathrm{Na}^{+}$into vacuoles. $\mathrm{Na}^{+} / \mathrm{H}^{+}$antiporters can be induced by external stimuli, transcript level of AtNHXI has been reported to be up-regulated by $\mathrm{NaCl}$ and $\mathrm{ABA}$, but not by cold [32]. The transcript of $O s N H X 1$ increased under condition of salt stress, but it was not induced by mannitol treatment [33]. In this study, the LeNHX3 expression was improved by salt, ABA treatments, and the highest expression occurs at low temperature treatment, however, the expression was not obviously affected by mannitol (Fig. 4B), this indicates that LeNHX3 is involved in salt, cold and ABA stresses response.

\section{CONCLUSION}

Results of molecular character and phylogeny indicates residue substitutions in LeNHX3 make it more conserved as a typical vacuole $\mathrm{Na}^{+} / \mathrm{H}^{+}$antiporter in compare to LeNHX3GB. Expression analysis showed that LeNHX3 gene is involved in the cross-talk of salt, low temperature and ABA response in wild type tomato. All results in this study showed that the transcript form of $L e N H X 3$ in wild type tomato is suitable as an important target gene for improving plant adverse stress tolerance by genetic manipulation in the future.

\section{CONFLICT OF INTEREST}

The authors confirm that this article content has no conflict of interest.

\section{ACKNOWLEDGEMENTS}

The authors thank the anonymous referees for careful reading and constructive suggestions. This work was supported by Scientific research fund of Sichuan provincial education department (08ZB051) and Educational reform project of Leshan Normal university (JG14-YB14).

\section{REFERENCES}

[1] Mishra S, Alavilli H, Lee Bh, Panda S, Sahoo L. Cloning and Functional Characterization of a Vacuolar $\mathrm{Na}^{+} / \mathrm{H}^{+}$Antiporter Gene from Mungbean $(\mathrm{VrNHX1})$ and Its Ectopic Expression Enhanced Salt Tolerance in Arabidopsis thaliana. PLoS ONE 2014; 9(10): e106678.

[2] Yousofinia M, Ghassemian A, Sofalian O, Khomari S. Effects of salinity stress on barley (Hordeum vulgare L.) germination and seedling growth. Int J Agric Crop Sci 2012; 4(18): 1353-1357.

[3] Hussain S, Khaliq A, Matloob A, Wahid M, Afzal I. Germination and growth response of three wheat cultivars to $\mathrm{NaCl}$ salinity. Soil Environ 2013; 32(1): 36-43.

[4] Lv D, Subburaj S, Cao M, et al. Proteome and Phosphoproteome Characterization Reveals New Response and Defense Mechanisms of Brachypodium distachyon Leaves under Salt Stress. Mol Cell Proteomics 2014; 13(2): 632-652.

[5] Kubo M, Augusto P, Cristianini M. Effect of high pressure homogenization $(\mathrm{HPH})$ on the physical stability of tomato juice. Food Res Int 2013; 51(1): 170-179.

[6] Bolarín M, Perez Alfocea F, Cano E, EstañM T, Caro M. Growth, fruit yield, and ion concentration in tomato genotypes after preemergence and post-emergence salt treatments. J Am Soc Horticult Sci 1993; 118(5): 655-660.

[7] Chookhampaeng S, Pattanagul W, Theerakulpisut P. Screening some tomato commercial cultivars from Thailand for salinity tolerance. Asian J Plant Sci 2007; 6(5): 788-794.

[8] Cano E, Pérez-Alfocea F, Moreno V, Caro M, Bolarín M. Evaluation of salt tolerance in cultivated and wild tomato species through in vitro shoot apex culture. Plant Cell, Tissue Organ Cult 1998; 53(1): 19-26.

[9] Baltierra F, Castillo M, Gamboa MC, Rothhammer M, Krauskopf E. Molecular characterization of a novel $\mathrm{Na}^{+} / \mathrm{H}^{+}$antiporter cDNA from Eucalyptus globulus. Biochem Biophys Res Commun 2013; 430(2): 535-540.

[10] Banjara M, Zhu L, Shen G, Payton P, Zhang H. Expression of an Arabidopsis sodium/proton antiporter gene (AtNHXI) in peanut to improve salt tolerance. Plant Biotechnol Rep 2012; 6(1): 59-67.

[11] Yin XY, Yang AF, Zhang KW, Zhang JR. Production and analysis of transgenic maize with improved salt tolerance by the introduction of $A t N H X 1$ gene. Acta Botanica Sinica 2004; 46(7): 854-861.

[12] Jha B, Mishra A, Jha A, Joshi M. Developing transgenic Jatropha using the $S b N H X 1$ gene from an extreme halophyte for cultivation in saline wasteland. PLoS ONE 2013; 8(8): e71136.

[13] Rodriguez-Rosales M, Jiang X, Gálvez F, Aranda M, Cubero B, Venema K. Overexpression of the tomato $\mathrm{K}^{+} / \mathrm{H}^{+}$antiporter LeNHX2 confers salt tolerance by improving potassium compartmentalization. New Phytologist 2008; 179(2): 366-377. 
[14] Huertas R, Rubio L, Cagnac O, et al. The $\mathrm{K}^{+} / \mathrm{H}^{+}$antiporter LeNHX2 increases salt tolerance by improving $\mathrm{K}^{+}$homeostasis in transgenic tomato. Plant Cell Environ 2013; 36(12): 2135-2149.

[15] Gálvez F, Baghour M, Hao G, Cagnac O, Rodríguez-Rosales M, Venema K. Expression of LeNHX isoforms in response to salt stress in salt sensitive and salt tolerant tomato species. Plant Physiol Biochem 2012; 51(2): 109-115.

[16] Fan J. Molecular cloning of LeNHX3 gene from tomato and construction of the Over-expression Vector. Jiangsu Agric Sci 2010; 3(6): 47-49. (In chinese)

[17] Arnold K, Bordoli L, Kopp J, Schwede T. The SWISS-MODEL workspace: a web-based environment for protein structure homology modelling. Bioinformatics 2006; 22(2): 195-201.

[18] Zhu J. Regulation of ion homeostasis under salt stress. Curr Opin Plant Biol 2003; 6(5): 441-445.

[19] Sun W, Xu X, Zhu H. Comparative transcriptomic profiling of a salt-tolerant wild tomato species and a salt-sensitive tomato cultivar. Plant Cell Physiol 2010; 51(6): 997-1006.

[20] Shi H, Ishitani M, Kim C, Zhu J. The Arabidopsis thaliana salt tolerance gene SOS1 encodes a putative $\mathrm{Na}^{+} / \mathrm{H}^{+}$antiporter. Proc Nat Acad Sci USA 2000; 97(2): 6896-6901.

[21] Wu S, Ding L, Zhu J. SOS1, a Genetic Locus Essential for Salt Tolerance and Potassium Acquisition. Plant Cell 1996; 8: 617-627.

[22] Bordoli L, Schwede T. Automated protein structure modeling with SWISS- MODEL Workspace and the Protein Model Portal. Methods Mol Biol 2012; 857: 107-136.

[23] Fraccalvieri D, Soshilov A, Karchner S, et al. Comparative analysis of homology models of the $\mathrm{AH}$ receptor ligand binding domain: verification of structure-function predictions by site-directed mutagenesis of a nonfunctional receptor. Biochemistry 2013; 52(4): 714-725.

[24] Min J, Zhang Y, Xu R. Structural basis for specific binding of Polycomb chromodomain to histone H3 methylated at Lys 27. Genes Dev 2003; 17(15): 1823-1828.
[25] Faure G, Bornot A, de Brevern A. Protein contacts, inter-residue interactions and side-chain modelling. Biochimie 2008; 90(4): 626639.

[26] Kozachkov L, Padan E. Site-directed tryptophan fluorescence reveals two essential conformational changes in the $\mathrm{Na}^{+} / \mathrm{H}^{+}$ antiporter NhaA. Proc Nat Acad Sci 2011; 108(38): 15769-15774.

[27] Zhang G, Zhang X, Chen Z. Phylogeny of cryptogrammoid ferns and related taxa based on rbcL sequences. Nordic J Botany 2003; 23(4): 485-493.

[28] Ohnishi M, Fukada-Tanaka S, Hoshino A, Takada J, Inagaki Y, Iida S. Characterization of a novel $\mathrm{Na}^{+} / \mathrm{H}^{+}$antiporter gene InNHX2

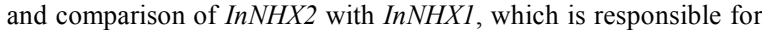
blue flower coloration by increasing the vacuolar $\mathrm{pH}$ in the Japanese morning glory. Plant Cell Physiol 2005; 46(2): 259-267.

[29] Wang S, Li Z, Rui R, Fan G, Lin K. Cloning and characterization of a plasma membrane $\mathrm{Na}^{+} / \mathrm{H}^{+}$antiporter gene from Cucumis sativus. Russ J Plant Physiol 2013; 60(3): 330-336.

[30] Wang X, Yang R, Wang B, Liu G, Yang C, Cheng Y. Functional characterization of a plasma membrane $\mathrm{Na}^{+} / \mathrm{H}^{+}$antiporter from alkali grass (Puccinellia tenuiflora). Mol Biol Rep 2011; 38(7): 4813-4822.

[31] Mahajan S, Pandey G, Tuteja N. Calcium-and salt-stress signaling in plants: shedding light on SOS pathway. Arch Biochem Biophys 2008; 471(2): 146-158.

[32] Shi H, Zhu JK. Regulation of expression of the vacuolar $\mathrm{Na}^{+} / \mathrm{H}^{+}$ antiporter gene $A t N H X 1$ by salt stress and abscisic acid. Plant Mol Biol Rep 2002; 50(3): 543-550.

[33] Fukuda A, Nakamura A, Tagiri A, et al. Function, intracellular localization and the importance in salt tolerance of a vacuolar $\mathrm{Na}^{+} / \mathrm{H}^{+}$antiporter from rice. Plant Cell Physiol 2004; 45(2): 146159.

Received: February 17, 2015
(C) Fan et al.; Licensee Bentham Open.

Revised: March 21, 2015

Accepted: June 09, 2015

This is an open access article licensed under the terms of the Creative Commons Attribution Non-Commercial License (http:/creativecommons.org/licenses/ by-nc/4.0/) which permits unrestricted, non-commercial use, distribution and reproduction in any medium, provided the work is properly cited. 